\title{
No need to go big Teaching Framework concepts with small teaching
}

$\mathbf{T}$ he ACRL Framework for Information Literacy for Higher Education encourages librarians to engage students with big ideas related to information creation, access, and use. ${ }^{1}$ One way that librarians may be able to do this is through a small teaching approach. In Small Teaching: Everyday Lessons from the Science of Learning, ${ }^{2}$ James M. Lang uses insights from educational research to highlight small instructional interventions that support student learning. Although Lang does not specifically call out librarians as instructors, some of these strategies could be used to engage students with Framework concepts, even within a single session.

In this essay, I focus on strategies in four areas-retrieving, predicting, connecting, and self-explaining. These were selected because they seem most applicable to a one-shot setting. For each, I describe models recommended by Lang and demonstrate how they could support increased understanding of Framework concepts. While none of these interventions by themselves may seem revolutionary to experienced instruction librarians, for some they may represent a new approach to intentionally teaching the Framework. While I have chosen to highlight only one Framework concept per category, there are likely ways to connect each strategy with any frame.

\section{Retrieving}

The first set of interventions that Lang recommends center around the retrieval effect, which holds that "if you want to retrieve knowledge from your memory, you have to practice retrieving knowledge from your memory." 3 Simply, the more times we are forced to practice retrieving knowledge, the better we remember it.

\section{Models_opening and closing questions} According to Lang, opening and/or closing questions are simple ways to incorporate retrieval practice. While opening questions may be challenging in a one-shot context, if you are working with a class multiple times, asking students to write down what was covered in the previous session rather than reminding them is an example of using this strategy. Even if you are unable to incorporate opening questions, most librarians likely have the opportunity to include closing questions, asking students to remember material just learned.

Many librarians already incorporate oneminute papers, muddiest points, or short quizzes. However, these are often completed as the final activity, when students are leaving the room, and are used for assessment rather than as a learning activity. Lang recommends making the retrieval activity the next-to-last

Jane Hammons is teaching and learning engagement librarian and assistant professor at The Ohio State University Libraries, email: hammons.73@osu.edu

(C) 2021 Jane Hammons 
activity of the session, to allow time to review responses.

\section{Implementing the strategy-Searching as} Strategic Exploration

The Searching as Strategic Exploration frame emphasizes that students need to be familiar with a range of different search strategies and tools, and match the appropriate tools to information needs.

Closing questions could be used to help students retain knowledge of new search strategies, resources, or concepts that were covered during a session. Students could be asked to respond, from memory, to questions such as:

- Which Boolean operator would you use to exclude certain words from your results?

- Why is it important to change your search strategy depending on your information need?

Students could also be given multiple scenarios in which someone needs information, select which of the resources covered that day would be most appropriate, and explain why. For example:

- In each of the following scenarios, indicate the search tool you would recommend. Explain why you think it would be appropriate.

Zoey needs several scholarly articles for her psychology research paper.

O Mia wants the most up-to-date information on the presidential election.

$\bigcirc$ Lucky is looking for basic facts about The Great Depression.

\section{Implementation tip}

Lang suggests the strategy will be more useful if students are required to actively apply what they learned through short-answer questions, rather than recall basic facts on a multiple-choice quiz. Also, having students give responses in writing can be more effective, as this requires all students to participate.

\section{Predicting}

The next set of strategies focus on predicting. The principle is simple: "making predictions about material that you wish to learn increases your ability to understand that material and retrieve it later." ${ }^{4}$ Lang outlines several reasons why prediction may improve learning. Students who are asked to make a prediction must activate any prior knowledge that they already have to identify an answer. Prediction activities also alert students to what the instructor considers important in the upcoming lesson. In addition, students "are forced to confront the depth of their knowledge, and that confrontationwhen it reveals gaps or weaknesses-might spur them to better or more determined learning." ${ }^{\circ}$ This may be especially appealing to librarians who frequently encounter students who are convinced they already know everything about research.

Models - pretesting, prediction-exposure-feedback The opening minutes of a class are ideal times to incorporate a prediction activity, according to Lang. Starting class with a brief pre-test is a one way to encourage students to make predictions. At other points in the session, students can be asked to make quick, informal predictions before being exposed to new material, and then be provided with immediate feedback.

\section{Implementing the strategy-Information Creation as a Process}

Information Creation as a Process emphasizes the need for students to be familiar with the variety of information creation processes, as well as the information formats that result from these processes, and to recognize that the creation process and format can impact how the information product is perceived.

To use prediction to help students understand this concept, a librarian could begin the session with a pre-test requiring students to match different information formats to the creation process or to indicate which information formats would be 
most appropriate for an information need. For example:

- Which type of information source is usually created by a researcher over a period of months (or years)? A blog post, a news article, or a scholarly journal article?

- Jasper's work assignment is to gather information on public reaction to his company's new product. Which of the following types of information sources would he likely want to use, and why? A book, social media posts, or a scholarly journal article?

In this activity, students have to draw upon what they already know about different information formats, their creation processes, and their (perceived) value or use. Reviewing their responses, you would gain insight into whether or not students are familiar with different information formats, and any student who struggles with the exercise would recognize a gap in their knowledge.

\section{Implementation tips}

Lang notes that it is important to be sure that students have at least some prior knowledge they can draw upon before asking them to make predictions. Asking a class of first-year students to predict which of 100 databases will be most useful for their research, when they don't have knowledge of any of the databases, will not be effective. It is also important that you correct inaccurate predictions fairly quickly, otherwise there is a risk that the incorrect response may become what is remembered.

\section{Connecting}

Connecting strategies are based on the fact that learners retain information better when they are able to connect new pieces of information with existing knowledge. Helping students to build comprehension involves "helping them forge rich, interconnected networks of knowledge-ones that enable each existing piece of information in our content area to connect with lots of other information, concepts, and ideas." ${ }^{6}$
These networks are what allow students to "see the bigger picture, make meaning, apply what they have learned into novel contexts, and more."

\section{Model-The Minute Thesis}

One option for helping students forge connections is an activity Lang calls the Minute Thesis. In this activity, students are asked to articulate connections between different concepts or themes. For example, in his literature courses, Lang provides students with a list of themes and a list of novels. Students must select one theme and write a brief thesis explaining how that theme is connected to two of the novels.

\section{Implementing the strategy-Scholarship as Conversation}

The Scholarship as Conversation concept is focused on the need for students to understand that scholars are engaging in ongoing debates and that through this process certain ideas may be accepted, expanded, or rejected.

A variation of the Minute Thesis activity could be a way to help students connect research activities that they are learning with Scholarship as Conversation. For example, you could show students a video or give a brief lecture explaining the concept. You could then provide them with a list of actions that they undertake as part of a research project, including developing a research question, conducting a literature review, and providing citations. Students could select one of the specific activities, and be given a minute to come up with a quick explanation for how that action is related to the idea of scholarship as an ongoing conversation. Reviewing a few of the responses could help students understand how different activities are all part of the bigger process of engaging in the scholarly debate.

\section{Implementation tip}

Lang emphasizes that our role as instructors is to create an environment in which students can make these connections, not 
make the connections for them. Telling them about the connections is not enough, but we can facilitate their ability to make the connections on their own.

\section{Self-explaining}

Another set of strategies described by Lang are focused on self-explaining, which emphasizes that "learners benefit from explaining out loud (to themselves or others) what they are doing during the completion of a learning task." ${ }^{8}$ Requiring students to describe what they are doing, and why, can encourage students to more critically consider their own actions and to "make connections between their knowledge and their skills." 9 One reason why selfexplaining may be effective is that it can help learners and instructors to identify the flawed understandings that may be driving certain actions.

\section{Models-Peer instruction, think aloud}

Putting this strategy into practice can be as simple as asking a question, giving students time to develop a response, having students justify their response to a peer, and providing feedback. Another way to incorporate self-explaining is to ask students to think aloud as they attempt a specific task. Again, this requires students to connect actions to knowledge, and gives you a chance to recognize where students might be going wrong with their reasoning.

\section{Implementing the strategy-Authority is Constructed and Contextual}

The Authority is Constructed and Contextual concept emphasizes that information sources have different levels of authority, that this authority is based (at least in part) on the expertise of the creator, and that context helps determine what types of sources (or who) may be considered authoritative.

Self-explaining could be used as a way for students to demonstrate their understanding of what makes a source authoritative. For example, you could ask students to consider two different types of sources and select the one they think would be more authoritative within a specific context. Students could share their response with a classmate, and provide an explanation for their viewpoint. The instructor could ask a few pairs to share and provide feedback to the group.

Or, after a lecture in which students are provided with guidance on evaluating sources, students could be given a specific source and be encouraged to talk through their evaluation process, explaining what they are thinking at each stage. They would need to articulate the steps they take to evaluate the source, and explain why they think the source would, or would not be, authoritative within the context.

\section{Implementation tip}

As with other strategies, it is important to note that self-explanations are most effective when students receive timely feedback.

\section{Conclusion}

The small teaching approach emphasizes that minor, but deliberate, changes in the way we teach and engage with students can have an impact on student learning. Incorporating a few of Lang's strategies could help librarians make the most of our limited time with students and help them better connect with Framework concepts.

\section{Notes}

1. "Framework for Information Literacy for Higher Education," (Chicago: ACRL, 2015).

2. James M. Lang, Small Teaching: Everyday Lessons from the Science of Learning (Jossey-Bass, 2016).
3. Ibid., 20.
4. Ibid., 43.
5. Ibid., 51.
6. Ibid., 96.
7. Ibid., 96.
8. Ibid., 138.
9. Ibid., 139. 